\title{
Genetic Diversity in the mtDNA control region and population structure of Chrysichthys nigrodigitatus from selected Nigerian rivers: Implications for conservation and aquaculture
}

\author{
Sylvanus A. Nwafili, Tian-Xiang Gao
}

Received - 26 February 2016/Accepted - 20 June 2016. Published online: 30 June 2016; $\odot$ Inland Fisheries Institute in Olsztyn, Poland Citation: Nwafili S.A., Gao T.X. 2016 - Genetic Diversity in the mtDNA control region and population structure of Chrysichthys nigrodigitatus from selected Nigerian rivers: Implications for conservation and aquaculture - Arch. Pol. Fish. 24: 85-97.

\begin{abstract}
Abstrakt. The genetic diversity and population structure of Chrysichthys nigrodigitatus were evaluated using a 443 base pair fragment of the mitochondrial control region. Among the eight populations collected comprising 129 individuals, a total of 89 polymorphic sites defined 57 distinct haplotypes. The mean haplotype diversity and nucleotide diversity of the eight populations were $0.966 \pm 0.006$ and $0.0359 \pm 0.004$, respectively. Analysis of molecular variance showed significant genetic differentiation among the eight populations $\left(F_{S T}=0.34 ; \mathrm{P}<0.01\right)$. The present results revealed that $C$. nigrodigitatus populations had a high level of genetic diversity and distinct population structures. We report the existence of two monophyletic matrilineal lineages with mean genetic distance of $10.5 \%$ between them. Non-significant negative Tajima's $D$ and Fu's Fs for more than half the populations suggests that the wild populations of $C$. nigrodigitatus underwent a recent population expansion, although a weak one since the late Pleistocene.
\end{abstract}

Keywords: Chrysichthys nigrodigitatus, mtDNA control region, Niger Delta, Niger River, Lagos Lagoon, Shiroro Lake

\footnotetext{
S.A. Nwafili [[”]

Department of Fisheries, Faculty of Agriculture

University of Port Harcourt, Nigeria

e-mail: nwafili4@gmail.com
}

T. X. Gao

Laboratory of Mariculture, Ocean University of China,

266003 Qingdao, PR China

\section{Introduction}

The silver catfish, Chrysichthys nigrodigitatus (Lacepéde), belongs to the subfamily claroteinae (Teugels 1996, Mo 1991). It is a highly valued food fish in Nigeria and other West African countries (Ezenwa 1981, Obiekezie and Enyenihi 1988). It occurs in freshwater and brackish-water systems of low salinity (Moses 2001) The silver catfish is a benthic omnivorous fish that migrates, though, to freshwater to breed (Nwafili et al. 2012). Erondu (1997) reported that $C$. nigrodigitatus undertake breeding migrations in response to environmental cues, and they are thought to be modulated by salinity. It is therefore likely that reducing water salinity during the months of rainfall may promote upstream breeding migrations. Juveniles migrate to saline waters in lagoons, swamps, and estuaries to feed and grow (Sivalingam 1975, Ezenwa 1981), and when it is time for breeding they migrate upstream from the more saline brackish waters to fresh water to spawn (Sivalingam 1975, Agnese 2000). C. nigrodigitatus provide parental care by building nests and spawning in hollow cavities or rock crevices where a sticky single egg-mass is deposited. In addition, fertilized eggs are incubated in the bucal cavity of the males. The effect of these suites of behavioral characteristics

\footnotetext{
(c) Copyright by Stanisław Sakowicz Inland Fisheries Institute in Olsztyn.

(C) 2016 Author(s). This is an open access article licensed under the Creative Commons Attribution-NonCommercial-NoDerivs License (http://creativecommons.org/licenses/by-nc-nd/3.0/).
} 
such as nesting and parental care in which males carry fertilized eggs in their bucal cavities make this fish a good candidate for approaches taking into account both genetic variation and genetic structure, as very little gene flow between populations would be expected.

Despite the ecological and economic importance of Nigerian rivers (particularly the Niger Delta), little is known about the genetic diversity of the fish species occurring in them. Freshwater and marine fishery resources in Nigeria are facing challenges of over-fishing and destruction of natural habitats by pollution (Adeyemo 2003). There are concerns in the Niger Delta of hazardous fishing methods, climate change, over-fishing, and pollution from industries and multinational oil companies, which can impact genetic diversity. The $C$. nigrodigitatus fishery in the Niger Delta targets gravid females that are migrating to spawn (Moses 1979, 1987). Bickham and Smolen (1994) and Bickham et al. (2000) suggest that reduced genetic diversity stemming from population bottlenecks and inbreeding could result from environmental alterations or the influence of anthropogenic factors. In a disrupted environment such as that in the Niger Delta, studies of population genetic diversity can provide valuable information that can aid in undertaking conservation measures and managing ecosystems and their populations.

There are only few genetic studies on $C$. nigrodigitatus in Nigeria. Ezenwa et al. (1986) studied different populations of species in Nigeria and found regional variations in fecundity and morphological characters. To understand better the genetic diversity and evolutionary divergence of different populations of $C$. nigrodigitatus, it is inevitable to use molecular markers. Kotoulas et al. (1991) found high level of microsatellite variation at three loci in five populations of this species in West Africa. Song et al. (2011) and Nwafili et al. (2015) studied the genetic polymorphism and population structure of $C$. nigrodigitatus from the Niger Delta and found moderate to high genetic diversity and two clades. However, the limited number of primer combinations in these studies prevented drawing more robust conclusions. A popular marker for studying population genetics and the demographic history of aquatic organisms is mtDNA (Lee et al. 1995, Buonnacorsi et al. 2001, Cho and Kim 2006, Wang et al. 2008), especially the control region because of its high evolutionary rate compared to many nuclear loci.

The genetic structure and diversity of fish populations is maintained by combinations of specific characteristics of the species, vagility, and the absence or presence of dispersal barriers. Freshwater fishes demonstrate low levels of genetic variations and high levels of genetic differentiation among populations (Gyllensten 1985); in contrast, Ward et al. (1994) and Avise (2000) suggest that organisms with close association with either freshwater or marine systems can display genetic structure and diversity that is in between the two. C. nigrodigitatus has a biphasic life history in which the juveniles and adults live in freshwater and estuaries. The scale of dispersal might be limited, in which case the species can be highly genetically subdivided. Alternatively, dispersal can be extensive during the adult and juvenile phase, which could lead to genetic homogeneity.

The main purpose of the present study was to examine the genetic diversity and structure of $C$. nigrodigitatus along the coast of Nigeria. In order to assess the degree of gene flow among the studied populations and to determine the genetic status of the species in the Niger Delta, we applied sequence analysis of the mtDNA control region. The results obtained are discussed in the contexts of the degree of migration, aquaculture, and the enhancement of species-specific conservation programs.

\section{Material and methods}

\section{Study area and sampling design}

The sampling sites were in the Niger Delta region, Lagos Lagoon (LA), downstream at Asaba (LN) and upstream at Jebba (UN) in the Niger River, and downstream at Shiroro (SH) in the Kaduna River (Fig. 1). In the Niger Delta, we sampled $C$. nigrodigitatus in the Cross River (CR), Buguma 


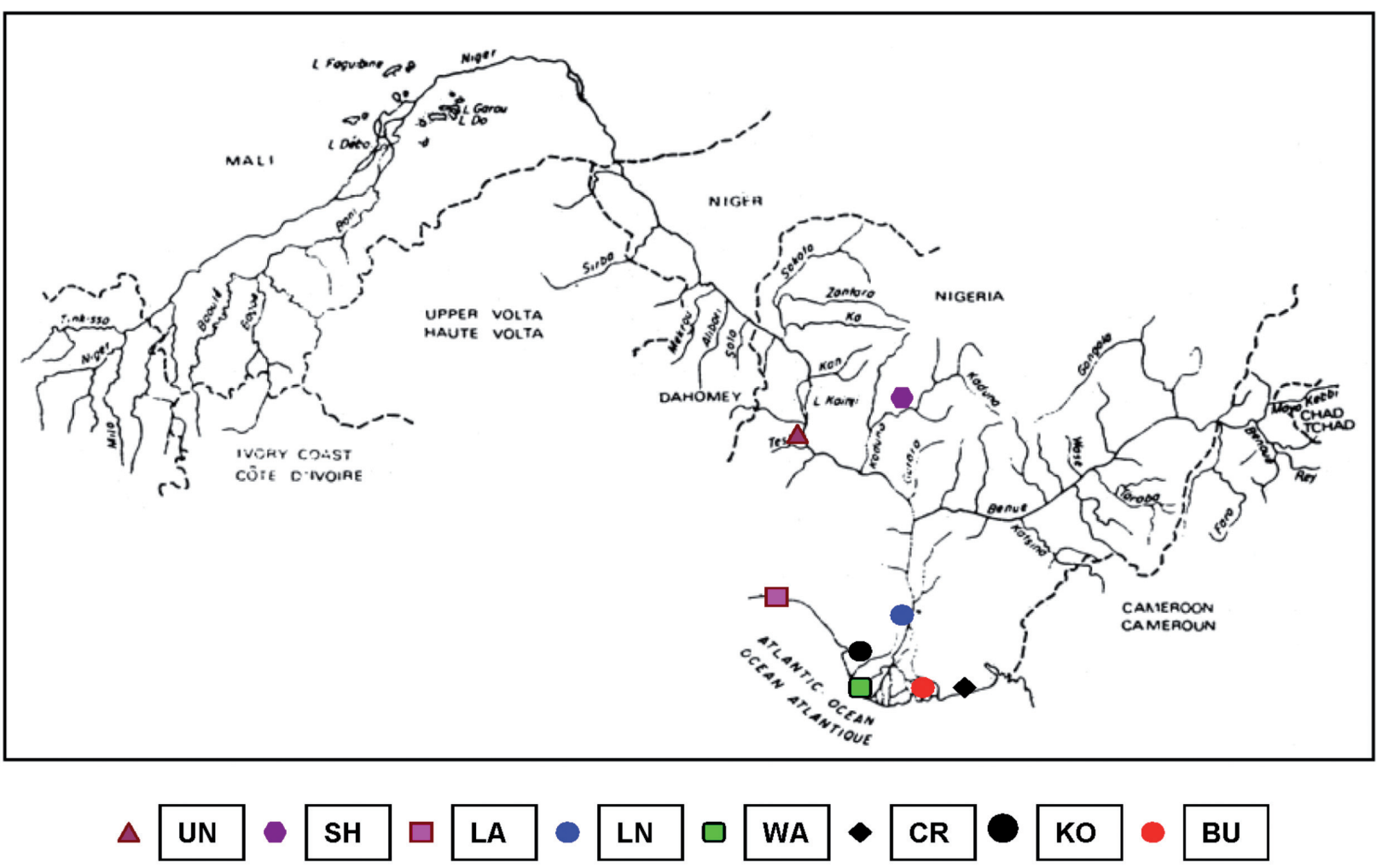

Figure 1. Map of study area, depicting Cross River (CR), Buguma Creek (BU), Lagos Lagoon (LA), Warri River (WA), Upper Niger River (UN), Lower Niger River (LN), Kaduna River (SH), Koko River (KO) and Kaduna River (SH).

brackish-water system (BU), Warri River (WA), and Benin River at Koko (KO). Samples from Epe, Badagry, and Badore were pooled to form the Lagos Lagoon population. Sampling was carried out between December 2008 and July 2009. Table 1 shows the sample size from each location.

\section{Genomic DNA extraction, PCR amplification, and sequencing}

Genomic DNA was isolated from muscle tissues. Muscle tissues were dissected and subsequently digested with proteinase $\mathrm{K}$ in a buffer of $10 \mathrm{mM}$ Tris- $\mathrm{HCl}(\mathrm{pH} 7.5)$ with $125 \mathrm{mM} \mathrm{NaCl}, 50 \mathrm{mM}$ EDTA, $8 \mathrm{M}$ urea, and 1\% SDS at $50^{\circ} \mathrm{C}$. DNA was then extracted in phenol-chloroform and

Table 1

Summary statistics of population genetic diversity among populations of $C$. nigrodigitatus including sample size (N), number of polymorphic sites $(P s)$, number of haplotypes $(H p)$, haplotype diversity $(h)$, nucleotide diversity (pi), and average number of nucleotide differences $(k)$

\begin{tabular}{llllllll}
\hline \hline ID & Location & $\mathrm{N}$ & $P s$ & $H p$ & $h$ & $p i$ & $k$ \\
\hline \hline WA & $5^{\circ} 21^{\prime}-6^{\circ} 00^{\prime} \mathrm{N}, 5^{\circ} 24^{\prime}-6^{\circ} 2^{\prime} \mathrm{E}$ & 14 & 16 & 10 & $0.95 \pm 0.05$ & $0.014 \pm 0.002$ & 5.94 \\
$\mathrm{BU}$ & $4^{\circ} 35^{\prime}-6^{\circ} 58^{\prime} \mathrm{N}, 6^{\circ} 58^{\prime}-6^{\circ} 0^{\prime} \mathrm{E}$ & 22 & 49 & 15 & $0.97 \pm 0.02$ & $0.03 \pm 0.09$ & 12.98 \\
$\mathrm{CR}$ & $4^{\circ} 25^{\prime}-7^{\circ} 00^{\prime} \mathrm{N}, 7^{\circ} 15^{\prime}-9^{\circ} 30^{\prime} \mathrm{E}$ & 20 & 7 & 3 & $0.57 \pm 0.06$ & $0.005 \pm 0.001$ & 2.38 \\
$\mathrm{LA}$ & $6^{\circ} 22^{\prime}-6^{\circ} 38^{\prime} \mathrm{N}, 3^{\circ} 23^{\prime}-3^{\circ} 43^{\prime} \mathrm{E}$ & 13 & 46 & 8 & $0.92 \pm 0.05$ & $0.049 \pm 0.006$ & 21.37 \\
$\mathrm{UN}$ & $9^{\circ} 50^{\prime}-10^{\circ} 55^{\prime} \mathrm{N}, 4^{\circ} 25^{\prime}-4^{\circ} 45^{\prime} \mathrm{E}$ & 16 & 52 & 8 & $0.91 \pm 0.04$ & $0.06 \pm 0.006$ & 25.83 \\
$\mathrm{SH}$ & $9^{\circ} 56^{\prime}-9^{\circ} 58^{\prime} \mathrm{N}, 6^{\circ} 51^{\prime}-6^{\circ} 54^{\prime} \mathrm{E}$ & 9 & 2 & 2 & $0.22 \pm 0.17$ & $0.001 \pm 0.00$ & 0.222 \\
$\mathrm{LN}$ & $5^{\circ} 50^{\prime}-6^{\circ} 14^{\prime} \mathrm{N}, 6^{\circ} 43^{\prime}-6^{\circ} 491 \mathrm{E}$ & 16 & 62 & 15 & $0.99 \pm 0.03$ & $0.039 \pm 0.01$ & 16.75 \\
$\mathrm{KO}$ & $5^{\circ} 51^{\prime}-6^{\circ} 00^{\prime} \mathrm{N}, 5^{\circ} 30^{\prime}-5^{\circ} 35^{\prime} \mathrm{E}$ & 19 & 12 & 7 & $0.75 \pm 0.07$ & $0.004 \pm 0.001$ & 1.94 \\
\hline \hline
\end{tabular}


precipitated in 100\% ethanol. Primers H16500 and L15923 (Watanabe and Nishida 2003), which targets a portion of the first $\left(5^{1}\right)$ half of the mtDNA control region and parts of the threonin (Thr) and proline (Pro) tRNA gene regions were used. Amplification reactions were in $50 \mu \mathrm{L}$ volumes containing 1.25 U Taq DNA polymerase (Takara Co., Dalian, China), 10-100 ng template DNA, $200 \mathrm{nmol} \mathrm{L}^{-1}$ forward and reverse primers, and $200 \mu \mathrm{mol}$ $\mathrm{L}^{-1}$ each of dNTPs, $10 \mathrm{mmol} \mathrm{L}{ }^{-1}$ Tris, $\mathrm{pH} 8.3,50 \mathrm{mmol}$ $\mathrm{L}^{-1} \mathrm{KCl}, 1.5 \mathrm{mmol} \mathrm{L} \mathrm{L}^{-1} \mathrm{MgCl}_{2}$. The PCR conditions consisted of 30-35 cycles of denaturation at $94^{\circ} \mathrm{C}, 15 \mathrm{~s}$; annealing at $52^{\circ} \mathrm{C}, 15 \mathrm{~s}$; and extension at $72^{\circ} \mathrm{C}, 30 \mathrm{~s}$ on a thermal cycler 9700 (Applied Biosystems, Foster City, CA, USA). PCR products were purified using Exo1 and SAP treatment (USB Corp., Cleveland, OH, USA). A $9 \mu \mathrm{l}$ portion of PCR product was mixed with $1.35 \mu \mathrm{l}$ of enzyme in $1.65 \mu \mathrm{l}$ of distilled water and placed in a thermal cycler at $37^{\circ} \mathrm{C}$ for 20 mins followed by an inactivation step of 30 mins at $80^{\circ} \mathrm{C}$ and then sequenced using the BigDye Terminator Cycle Sequencing Kit (ver.2.0, PE Biosystems, Foster City, California) on automated DNA sequencer (ABI Prism 377).

\section{Data analysis}

All the sequences were edited and aligned using Dnastar software (DNASTAR Inc., Madison, WI USA). Mitochondrial DNA diversity in the control region was evaluated using molecular diversity indices such as haplotype diversity $(h)$, nucleotide diversity (pi), polymorphic sites (Ps), and the mean number of pairwise differences $(k)$ for each population using DNASP (Librado and Rozas 2009). The genetic distances among haplotypes were estimated by using Kimura-2-parameter model (Kimura 1980).

To determine the best substitution model, hierarchical likelihood ratio tests were carried out with the MODELTEST 3.6 (Posada and Crandall 1998) and PAUP4.0b4a (Swofford 1998) programs for Windows. The optimum substitution model for the mtDNA data and the gamma distribution shape parameter for the rate of heterogeneity among sites that were generated were then used for the following analyses including the phylogenetic relationship of haplotypes and the analysis of molecular variance (AMOVA). The best likelihood scores were obtained with Tamura-Nei with gamma shape parameter $\gamma=$ 0.73 . The relationships among haplotypes were assessed by the total number of nucleotide differences between each pair of haplotypes that was used to generate a minimum-spanning tree (Excoffier and Smouse 1994). In addition the haplotype data, it was analyzed phylogenetically with the neighbor-joining (NJ) method implemented in the MEGA2.1 program (Kumar et al. 2001). Support for the NJ tree was assessed using 1000 bootstrap replications.

A hierarchical molecular variance analysis (AMOVA) and the conventional population $F_{S T}$ comparisons were performed in ARLEQUIN 3.1 (Excoffier et al. 2005) to test for significant population genetic structure and partition variance within $C$. nigrodigitatus (Excoffier et al. 1992). In addition, the AMOVA analysis was also carried out with the eight populations lumped into three groups as follows: LA, BU, and CR (Brackish), UN, LN, and SH (Freshwater), and WA and KO (Freshwater and Brackish).

To gain insight into the demographic history of $C$. nigrodigitatus, mismatch distribution analyses was implemented in Arlequin 3.1 (Excoffier et al. 2005). Mismatch distribution analyses describe pairwise differences among individuals within a given population. After a burst of growth the mismatch distribution approximates a smooth curve with a single, well-defined peak, whereas in a steady-state population with a constant population size the distribution is usually multimodal (Rogers and Harpending 1992).

Two tests of neutrality, Tajima's $D$ statistic (Tajima 1989) and Fu Fs (Fu 1997), were used to detect signatures of population demographic changes (bottlenecks or expansions) and deviations from the pattern of polymorphism expected from a neutral model of evolution. The examination of deviation from neutrality by both $D$ and $F$ s indices was based on 1000 coalescent simulations. Expectations of these statistics are nearly zero in a constant-size population; significant negative values indicate a sudden expansion in population size, whereas significant positive values indicate processes such as a 
population subdivision or recent population bottlenecks. Tajima's $D$ tests for differences between two estimators of $\theta$ s and $\theta \pi$. Fu's $F$ s statistic is negative if there is an excess of alleles over that expected for a given estimate of $\theta \pi$, which is powerful for detecting population expansion and hitchhiking ( $\mathrm{Fu} 1997)$. Demographic changes in C. nigrodigitatus were also examined by calculating the raggedness index of the observed mismatch distribution for each of the populations according to the population expansion model implemented in Arlequin 3.1. This measure quantifies the smoothness of the mismatch distribution. Small raggedness values represent a population which has experienced sudden expansion, whereas higher values of the raggedness index suggest stationary or bottlenecked populations (Harpending 1994, Harpending et al. 1993).

Table 2

Distribution of mtDNA Haplotypes of a 443-bp fragment of the control region among sequences of $C$. nigrodigitatus by site. Site abbreviations as in Fig. 1

\begin{tabular}{|c|c|c|c|c|c|c|c|c|}
\hline & CR & $\mathrm{SH}$ & $\mathrm{KO}$ & $\mathrm{BU}$ & UN & WA & $\mathrm{LN}$ & LA \\
\hline HAP1 & & & 1 & 1 & 3 & 3 & 1 & \\
\hline HAP2 & & & & 1 & & & & \\
\hline HAP3 & & & & & & & 1 & \\
\hline HAP4 & & & & & & & 1 & \\
\hline HAP5 & & & & & 3 & & & \\
\hline HAP6 & & & & & & & 1 & \\
\hline HAP7 & & & & & & 1 & 1 & \\
\hline HAP8 & & & & & & 1 & & \\
\hline HAP9 & & & & & & & & \\
\hline HAP10 & & & & 2 & & 1 & & \\
\hline HAP11 & & 8 & & & & & & \\
\hline HAP12 & & 1 & & & & & & \\
\hline HAP13 & & & & & & & 1 & \\
\hline HAP14 & & & & & 1 & & 1 & \\
\hline HAP15 & & & & & & & 1 & \\
\hline HAP16 & & & & & & & 1 & \\
\hline HAP17 & & & & & & & & 1 \\
\hline HAP18 & & & & & & 2 & 2 & \\
\hline HAP19 & & & & & & & 1 & \\
\hline HAP20 & & & & & & & 1 & \\
\hline HAP21 & & & & & & 1 & & \\
\hline HAP22 & & & & 2 & & & & \\
\hline HAP23 & & & & 1 & & & & \\
\hline HAP24 & & & & 1 & & & & \\
\hline HAP25 & & & & 3 & & & & \\
\hline HAP26 & & & & 1 & & & & \\
\hline
\end{tabular}

\begin{tabular}{|c|c|c|c|c|c|c|c|c|}
\hline & $\mathrm{CR}$ & $\mathrm{SH}$ & $\mathrm{KO}$ & $\mathrm{BU}$ & UN & WA & $\mathrm{LN}$ & LA \\
\hline HAP27 & & & & 2 & & & & \\
\hline HAP28 & & & & 1 & & & & \\
\hline HAP29 & 1 & & & & & & & \\
\hline HAP30 & 8 & & & 2 & & & & \\
\hline HAP31 & & & & & & 1 & & \\
\hline HAP32 & & & & & & 1 & & \\
\hline HAP33 & 11 & & & & & & & \\
\hline HAP34 & & & & 1 & & & & \\
\hline HAP35 & & & & 1 & & & & \\
\hline HAP36 & & & & & & & & 3 \\
\hline HAP37 & & & 7 & & & 2 & & 2 \\
\hline HAP38 & & & & & & 1 & & \\
\hline HAP39 & & & 1 & & & & & \\
\hline HAP40 & & & & & & & & 1 \\
\hline HAP41 & & & 7 & & & & & 1 \\
\hline HAP42 & & & 1 & & & & & \\
\hline HAP43 & & & 1 & & & & & \\
\hline HAP44 & & & 1 & & & & & \\
\hline HAP45 & & & & & & & & 2 \\
\hline HAP46 & & & & & & & & 2 \\
\hline HAP47 & & & & & & & & 1 \\
\hline HAP48 & & & & 2 & & & & \\
\hline HAP49 & & & & 1 & & & & \\
\hline HAP50 & & & & & & & 1 & \\
\hline HAP51 & & & & & & & 1 & \\
\hline HAP52 & & & & & 3 & & & \\
\hline HAP53 & & & & & 2 & & 1 & \\
\hline HAP54 & & & & & 1 & & & \\
\hline HAP55 & & & & & 1 & & & \\
\hline HAP56 & & & & & 1 & & & \\
\hline HAP57 & & & & & 1 & & & \\
\hline
\end{tabular}

Rough dates of population expansion were estimated with the formula $\mathrm{T}=\tau / 2 \mathrm{u}$ (Rogers and Harpending 1992), where $T=$ time since expansion, $\tau$ is expansion time, and $2 u=\mu$ (mutation rate) $\times$ generation time $\times$ number of bases sequenced. The sequence divergence of a 3-12\% mutation rate for the control region was used to determine the expansion time since the molecular clock for the control region of fishes vary among different groups of taxa.

To determine whether the geographic distance influenced the genetic structure of the contemporary population, the IBDWS v. 3.15 (Isolation by Distance Web Service) program was used to investigate the existence of any correlation between genetic distance and geographic distance using partial Mantel tests. Genetic distances (standard $F_{S T}$ ) were calculated with the program from the DNA data matrices using 
the K2P model of nucleotide substitution. These analyses were conducted with raw data as well as with log (geographic distance) as the ranges of some of the geographic distances were large. The maximum number $(30,000)$ of randomizations the program allows was used in all analyses.

\section{Results}

\section{Intraspecific sequence variation}

The PCR product amplified by primers H16500 and L15923 varied between 513 and 514 (20 individuals) after removing the primer parts. Following alignment using the default settings in Clustal X, a total of 522 consensus bp sequences was obtained for 129 specimens. Comparison with samples from some species of Pseudobagrus (Watanabe and Nishida 2003) confirmed that the sequence obtained by us included the first (5') half of the mtDNA control region (443 bp) and parts of the threonin (Thr) and proline (Pro) tRNA gene regions (109 bp). Only the control region fragment was used for further analyses. The nucleotide composition of the control region fragment was $\mathrm{A}^{\wedge} \mathrm{T}$-rich (A, 28.5\%; T, 34.3\%).

A total of 86 variable sites was found in the region, defining a total of 57 haplotypes. Only eight of these haplotypes were shared among populations (Table 2). HAP1 was the commonest haplotype occurring in five populations (KO, BU, UN, WA and LN), followed by HAP37 which occurred in three populations (KO, WA and LA). The Shiroro population $(\mathrm{SH})$ from a tributary of the Niger River, with its relatively small sample size, had only two haplotypes, which were unique. Five indels were detected in the mtDNA control region.

The intrapopulation diversity parameters of these populations of $C$. nigrodigitatus are shown in Table 1. Haplotype diversity $(h)$ was high for all populations except Shiroro (SH), and it ranged from 0.22 \pm 0.17 in SH to $0.99 \pm 0.03$ in LN. Nucleotide diversity (pi) varied among populations ranging from $0.001 \pm 0.00$ in SH to $0.06 \pm 0.006$ in UN (Table 1); overall, $\mathrm{h}=0.966 \pm 0.006, \mathrm{pi}=0.0359 \pm 0.0040$ and $k=15.15$.

The genetic distance based on Kimura-2 parameter varied between 0.012-0.074 (1.2 and 7.4\%) among populations (Table 3 ). The mean net genetic distance based on Tamura-Nei with $\gamma=0.73$ between Clade A and Clade B was 9.3\% while that between the subclades in Clade A was 5.1\% (Fig. 2).

\section{Population genetic structure}

The results of the AMOVA analysis (Table 4) attributed $66.52 \%$ of the variance to differences within populations, and overall $F_{S T}$ was significant $\left(F_{S T}=\right.$ $0.34 ; \mathrm{P}<0.01)$. The inter-population $F_{S T}$ genetic differentiation was $33.48 \%$. Hierarchical analysis using freshwater or brackish-water collection sites as grouping criterion (group 1; WA and $\mathrm{KO}$, group 2; LA, BU and CR, and group 3; LN, UN and SH) revealed that the majority $(65.76 \% ; \mathrm{P}<0.01)$ of

Table 3

Pairwise FST (lower half of diagonal) and Kimura-2-P genetic distance between populations (upper half of diagonal)

\begin{tabular}{lllllllll}
\hline \hline & KO & BU & UN & WA & LN & SH & LA & CR \\
\hline \hline KO & & 0.027 & 0.069 & 0.017 & 0.034 & 0.020 & 0.042 & 0.013 \\
BU & 0.340 & & 0.074 & 0.024 & 0.038 & 0.028 & 0.050 & 0.022 \\
UN & 0.530 & 0.370 & & 0.070 & 0.069 & 0.070 & 0.072 & 0.072 \\
WA & 0.496 & 0.064 & 0.433 & & 0.029 & 0.015 & 0.048 & 0.012 \\
LN & 0.367 & $0.033^{*}$ & 0.242 & $0.061^{*}$ & & 0.028 & 0.054 & 0.030 \\
SH & 0.854 & 0.306 & 0.466 & 0.505 & 0.190 & & 0.047 & 0.018 \\
LA & 0.373 & 0.179 & 0.192 & 0.314 & 0.130 & 0.390 & 0.045 \\
CR & 0.675 & 0.126 & 0.547 & 0.293 & 0.245 & 0.779 & 0.421 & \\
\hline \hline
\end{tabular}

All $\mathrm{P}<0.05$ except those indicated by * where $\mathrm{P}>0.05$ 
variation is found within populations. However, $4.59 \%(\mathrm{P}=0.24)$ of the genetic variation was explained by differences among groups. The amount of variance among populations within groups was $29.65 \%$, and it was significant, implying subdivision or heterogeneity associated with the type of water body or collection site. Overall, significant genetic population structure existed in the range of $C$. nigrodigitatus so far evaluated. Only two of the pairwise $F_{S T}$ estimates were not significant (Table 4), indicating that variation among populations was high.

A haplotype network and neighbor-joining tree are shown in Figs. 2 and 3. In this study, the neighbor-joining tree revealed two divergent clades among the eight populations of $C$. nigrodigitatus. Clade A, supported by a strong bootstrap value (Fig. 2), contained $15.55 \%$ of the total individuals sampled and was further divided into two lineages. Clade B contained $84.45 \%$ of the total individuals sampled and was also supported by a strong bootstrap value (Fig. 2). There were, however, no clusters corresponding to sampling localities. Clade A consisted of haplotypes from BU, UN, LN, and LA. The comprised representatives of each population. Thus, there was also no discernible clustering of the haplotypes into freshwater or brackish-water populations (Figs. 2 and 3). The genetic divergence between the two clades was estimated to be $10.5 \%$. There is no pattern of isolation by distance in the species $(\mathrm{Z}=$

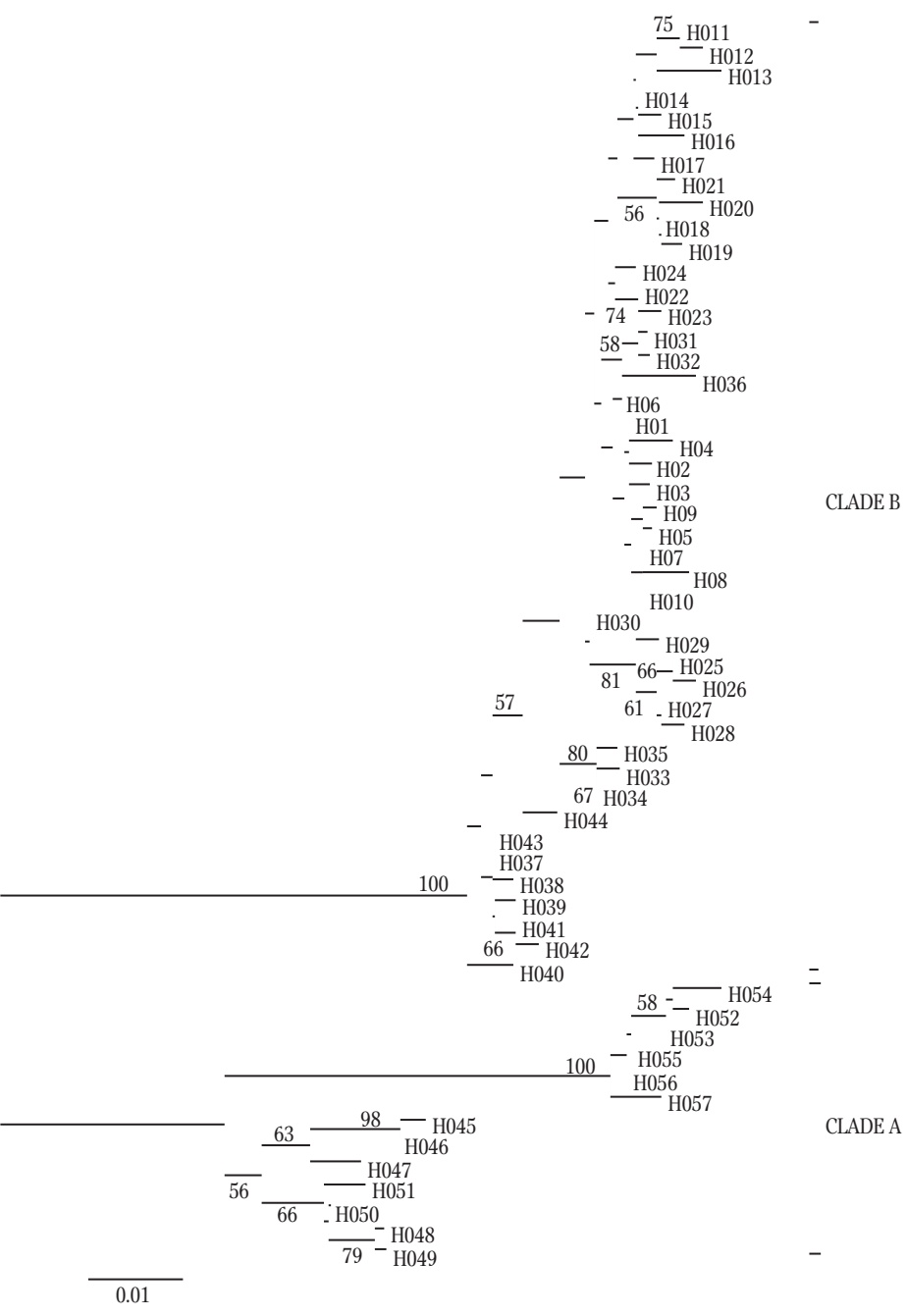

Figure 2. Interrelationship among C. nigrodigitatus sampled across Nigeria using the neighbor-joining method showing two major clades.

Table 4

Results of a hierarchical analysis of molecular variance in $C$. nigrodigitatus

\begin{tabular}{lllllll}
\hline \hline Localities & Source of variation & d.f. & $\begin{array}{l}\text { Variance } \\
\text { components }\end{array}$ & $\begin{array}{l}\text { Percentage } \\
\text { of variation }\end{array}$ & F statistic & P value \\
\hline \hline All localities & Among populations & 7 & 3.35524 & 33.48 & & \\
& Within populations & 121 & 6.66729 & 66.52 & $F_{S T}=0.34$ & $<0.01$ \\
& Total & 128 & 10.13818 & & $F_{C T}=0.06$ & $<0.24 \pm 0.01$ \\
Groups & Among groups & 2 & 0.46484 & 4.59 & $F_{S C}=0.31$ & $<0.01$ \\
& Within groups & 5 & 3.00605 & 29.65 & $F_{S T}=0.34$ & $<0.01$ \\
& Within populations & 121 & 6.66729 & 65.76 & & \\
\hline \hline
\end{tabular}




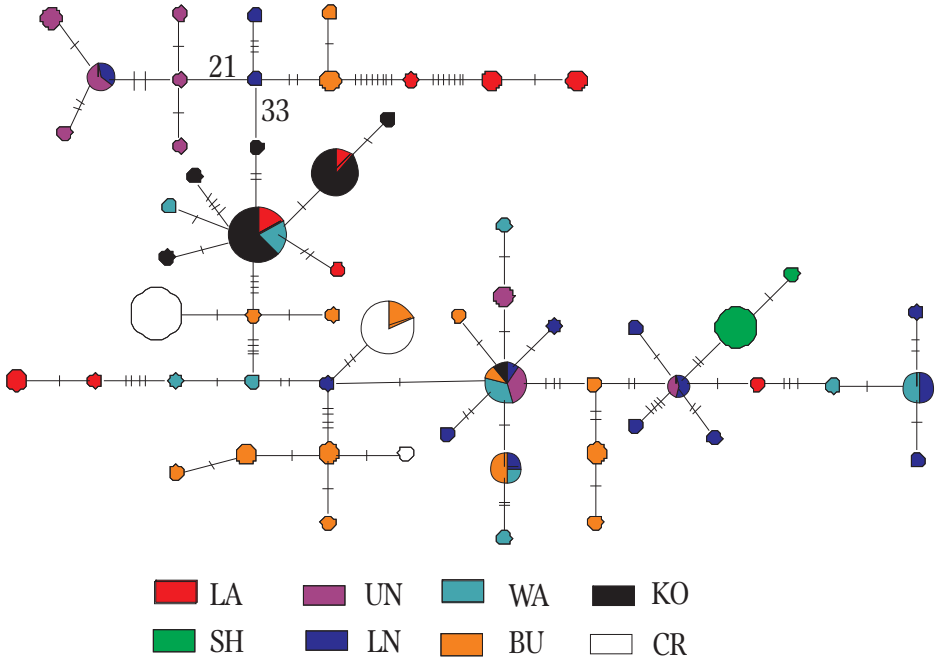

Figure 3. Reduced median-networks showing genetic relationship among control region. The sizes of circles are proportional to haplotype frequency. Haplotypes are represented by names that corresponds to Fig. 3 and Table 1.

pattern, which disallowed predicting its demographic history.

Neutrality tests of Tajima's $D$ revealed non-significant negative values in three individual populations ( $\mathrm{BU}, \mathrm{LN}$ and $\mathrm{SH})$. The nonsignificant Tajima's $D(\mathrm{P}>0.05)$ for these populations support the hypothesis that mtDNA control region mutations for $C$. nigrodigitatus are selectively neutral in those collection sites. However, the $\mathrm{KO}$ was an exception, with significant Tajima's $D(\mathrm{P}<0.05)$, supporting possible population expansion within that sampling locality. Non-significant negative Fu's Fs values were also obtained for these populations including WA which showed a non-significant positive Tajima's $D$. Fu's Fs is considered to be more sensitive in detecting population expansion and suggest-

migration is much greater than expected for an euryhaline species inhabiting fresh and brackish waters.

\section{Population demographics}

The mismatch distribution for the pooled populations showed a multimodal pattern characteristic of population differentiation which corresponds to demographic growth and a subsequent bottleneck. Because of the divergent clades, the different clades were examined to understand the population demography of $C$. nigrodigitatus. The mismatch analysis of Clade B haplotypes produced a unimodal distribution (Fig. 3) with a mean value of 6.29. Tajima's $D$ and Fu's Fs tests of Clade B agrees well with the mismatch analyses. The Tajima's $D$ was negative, -0.72 , but insignificant at $5 \%$ level $(\mathrm{P}=0.27)$. The Fu's Fs was negative (-22.23) and highly significant $(\mathrm{P}<$ 0.01). Both indicated a demographic expansion for clade B. The value of age expansion parameter $\tau$ was 7.33. The expansion time was estimated at 68,000-275,000 years ago. For Clade A, the mismatch distribution displayed a multimodal distribution. The Tajima's $D(1.80118 ; \mathrm{P}=0.98)$ and Fu's Fs $(0.59188 ; \mathrm{P}=0.64)$ were both positive $(\mathrm{P}<0.05)$. Clade A exhibited a discontinuous multimodal ing possible past population growth, but the expansion might have been restricted to separate local areas that resulted in the non-significant negative Fu's Fs values for some populations. The non-significant or small negative values of Tajima's $D$ and Fu's $F$ s found in half of the populations also suggest stationarity or weak expansion in $C$. nigrodigitatus populations.

The calculated raggedness index under the demographic expansion model for each population showed that many populations had a low raggedness index, ranging from 0.014097222 in $\mathrm{LN}$ to 0.59110803 in CR. SH had the next highest raggedness index of 0.35802469. Low Raggedness index for some of these populations were indications of population expansion.

\section{Discussion}

\section{Genetic diversity}

The capability of the fingerlings, juveniles, and adults to undertake migrations could contribute to shaping the genetic diversity and population structure of the populations examined in the current study. Microsatellite analysis of five populations of $C$. 
nigrodigitatus excluding any Nigerian population revealed high levels of genetic variability comparable to marine species (Kotoulas et al. 1991). In this study, the pattern of genetic polymorphism in the $C$. nigrodigitatus mtDNA control region is high and similar to those described for Plecoglossus altivelis (Temminck \& Schlegel) (Iguchi et al. 2002), Lutjanus argentimaculatus (Forsskål) (Ovenden and Street 2003), Brachyplatystoma rousseauxii (Castelnau) (Batista and Alves-Gomes 2006), Sicyopterus japonicus (Tanaka) (Watanabe et al. 2006), Colossomma macroponum (Cuvier) (Santos et al. 2007), some cichlids of Lake Tanganyika (Koblmüller et al. 2007, Sefc et al. 2007), and Tenualosa ilisha (Hamilton) (Mazumder and Alam 2009). The high genetic variability of the control region in $C$. nigrodigitatus could derive in part from a combination of the high mutation rate of the region, active dispersal of juveniles and adults, and the existence of many rare or private haplotypes (about $86 \%)$, that is, population-specific haplotypes. These suggest that the populations might have had a long history evolving independently and maintained large population sizes. These population-specific haplotypes can be used as population genetic markers (Slatkin 1985) for conservation.

All the populations from the Niger Delta, with the exception of CR, exhibited high genetic diversity comparable to populations from the Niger River and the Lagos Lagoon (Table 1). The active dispersal ability of the juveniles and adults could enable them to move swiftly from environments affected by pollution, and this could also account for the high genetic diversity in the Niger Delta populations. However, populations from $\mathrm{SH}$ and $\mathrm{CR}$ were characterized by less genetic variation. $C$. nigrodigitatus fisheries are well documented in the Cross River system (e.g., Moses 1979, 1987, 2001). Anecdotal evidence shows that human activities targeting migrating gravid females and used poison to fish in the CR (Moses 1987), while the use of fish poison, the "beat and pack” system (Nwafili 1997), and the dam effect in SH could be responsible for the low genetic variability in the two populations, respectively. Disturbances such as these frequently lead to bottleneck and reduced population size, which could result in low genetic variability. Ichthyologists have been concerned with the effect of dams on the exchange of genetic materials and because the assessment of damming effects on gene exchange among fish populations can provide useful knowledge for the sustainable management of wild resources, it is expedient to sample the upstream Kaduna River and the Niger River to determine the effect of the dams at Kainji and Shiroro on the genetic structure and diversity of existing C. nigrodigitatus populations. Taken together, the present study suggests that the $C$. nigrodigitatus resource of the Niger Delta is likely in good condition given the level of genetic variation.

The haplotype genetic distances among populations ranged from 1.2 to $7.4 \%$. The genetic distance was greatest between the Niger River populations (LN, UN) and others. According to Billington and Hebert (1991), haplotype divergence within species may commonly be under $10 \%$. Using the same mtDNA control region, Tsipas et al. (2009) found pairwise sequence divergence at the level of $10.25-12.09 \%$ between two cyprinids haplotypes as well as $0.0-2.15 \%$ within each species. However, since the control region is highly variable, more conserved markers such as mtDNA 16SrRNA and cyt b gene should be employed to verify the species status of $C$. nigrodigitatus in Nigerian waters.

\section{Genetic structure}

The presence of many private haplotypes may indicate that gene flow between studied populations is low, which provide strong support for the two genetic clusters, clearly rejecting a hypothesis of a single genetic assembly. An Analysis of variance (AMOVA) shows that within population variation $(66.52 \%)$ accounts for significantly more of the total genetic variation than among populations, indicating little gene flow and substantial genetic substructuring. Significant population structure as observed between populations was also evident from the significant pairwise $F_{S T}$. Freshwater or brackishwater habitat, limited long-distance dispersal of the adult and 

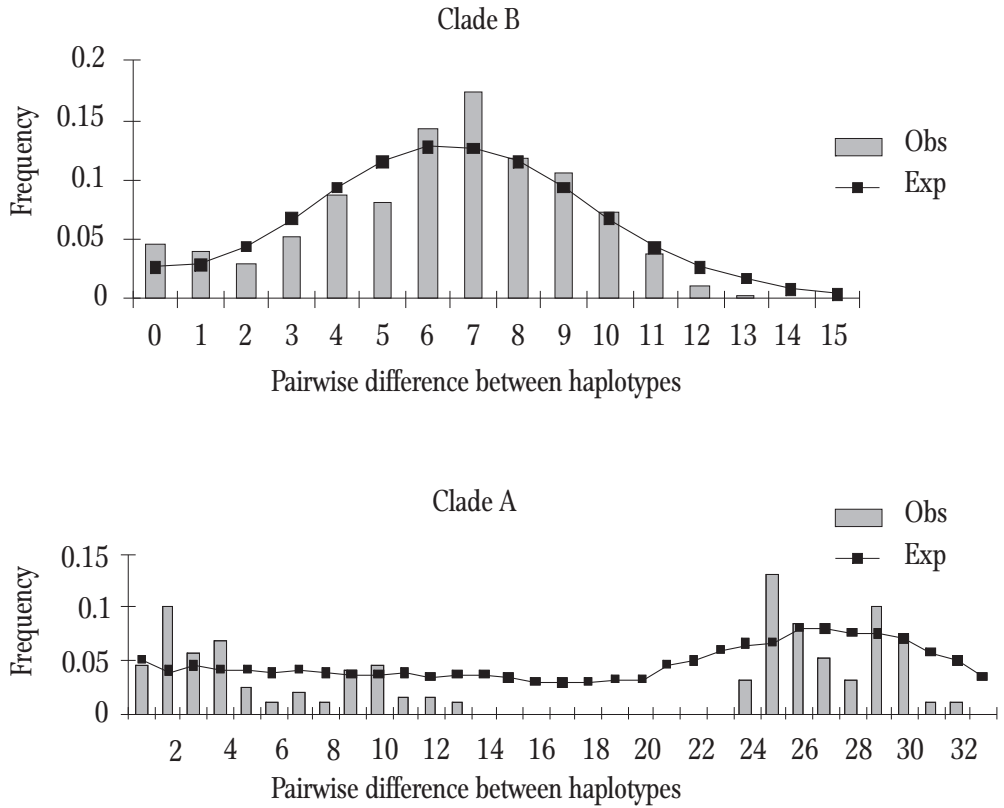

Figure 4. Mismatch distribution of $C$. nigrodigitatus mtDNA control region, Clade A, and Clade B.

juveniles and physical barriers may be responsible for the current genetic structure. The geographical distance of between the two sampling locations on the Niger River is above $600 \mathrm{~km}$, ad this, coupled with the meandering nature of the river, could effectively limit the degree of gene flow among populations. Distinct structuring patterns have been reported for many freshwater and estuarine species (Alves et al. 2001, Knight et al. 2009); however, it is possible periodic flooding events played a key role in connecting populations to produce the current genetic structure. The species appears to show no concordance with geographic barriers. The lack of any genetic signature of isolation could indicate that the degree of migration is greater than imagined for this euryhaline species using both fresh and brackish waters.

\section{Population demographics}

The demographic history of $C$. nigrodigitatus presents a complex picture, showing evidence of historical range expansion and bottleneck. The multimodal pattern of the mismatch distribution of the pooled population is characteristic of population differentiation corresponding to demographic growth and a subsequent bottleneck. It is probable that the loss of haplotypes due to a recent bottleneck event would have caused the multimodal mismatch distribution. The mismatch distribution (Fig. 4) for Clade B was unimodal, but it was multimodal for Clade A. The multimodal mismatch distribution in Clade $\mathrm{A}$ and the associated positive Tajima's $D$ and Fu's $F$ s suggest that the lineage had not always been stable. For Clade B, the Fu's Fs was negative and significantly deviated from a neutral state, indicating a population expansion. This distribution pattern was expected for a population under the sudden expansion model. However, Tajima's $D$ was negative and statistically insignificant. It is believed that population expansion and mutation rate heterogeneity have opposite effects on Tajima's $D$ statistics; therefore, this may explain the discrepancy between Fu's $F$ s and Tajima's $D$ statistics (Aris-Brosou and Excoffier 1992). Moreover, the high gamma distribution parameter $(\gamma=0.73)$ might mask the statistical significance. The non-significant Tajima's $D$ indicator could indicate that the populations of $C$. nigrodigitatus examined in this Clade are in genetic equilibrium, which suggests they are not under selective pressure for the mtDNA control region. Alternatively, it indicates that support for population expansion is weak. While population expansion was rejected by Tajima's $D$ and Fu's Fs statistic tests in three populations (CR, LA and UN), the high raggedness index estimated for populations $\mathrm{SH}$ and CR suggests the occurrence of bottleneck events. This is consistent with the history of collection sites for both SH and CR populations (Moses 1987, Nwafili 1997). The collection site for UN was between Lake Jebba and Lake Kainji on the Niger River. The two dams constructed on the Niger River at Jebba and Kainji are very close to each other and have resulted in the isolation of the UN population as evidenced by non-significant positive Tajima's $D$. The estimate of expansion time for populations from 
Clade B suggested a late Pleistocene event at 68,000-275,000 years ago. The distribution and demography of species worldwide was driven by environmental oscillations in the Pleistocene (Hewitt 1996, 2000). During the Pleistocene in West Africa, cyclic changes of arid conditions during the glacial maxima and wet tropical conditions in the interglacials could have resulted in the contraction and expansion of aquatic habitats (Lévêque 1997). While the series of contractions during the glacial maxima might have ensured the isolation of some populations in refuge zones, the wet periods in the interglacials could have resulted in the rapid population expansion to the contemporary pattern of genetic signature in $C$. nigrodigitatus. The distinct lineages were the likely consequences of isolation of populations in refuge zones and their subsequent recolonization of expanded habitats by the bottlenecked populations.

\section{Implications for conservation and aquaculture}

The results of this study suggest there are at least two highly divergent matrilineal lineages of $C$. nigrodigitatus in Nigerian waters. The low levels of genetic diversity in Cross River and in the downstream segment of the Kaduna River at Shiroro implies an urgent need to adopt protection measures and conservation programs for population recovery. Severe population declines can be identified by decreased genetic diversity (Lavery et al. 1996, Glenn et al. 1999). The private haplotypes revealed in the study can be utilized as genetic tags to select the proper source stocks for future aquaculture programs. Because the aquaculture of $C$. nigrodigitatus continues to expand, knowledge about the genetic characteristics of the populations renders it possible to select appropriate fish material for aquaculture purposes. As the culture of $C$. nigrodigitatus expands, care must be taken when selecting broodstock; broodstock must be selected from residing populations. This study provides baseline information with which $C$. nigrodigitatus populations can be evaluated in the future. Furthermore, the information obtained from the current study data highlight the necessity of preserving different habitats to ensure the genetic diversity of the species. It is very important to think about enhancing the Shiroro fishery, but before this, the upstream segment of the Kaduna River should be sampled genetically. It is also necessary to use more sensitive molecular markers, for example, microsatellites, to study some of these populations and gain more insight into the diversity and population genetic structure of $C$. nigrodigitatus.

Acknowledgments. We would like to thank the students of the Laboratory of Fisheries Ecology of the Ocean University of China, Qingdao for their support. This research was funded by the China post-doctoral foundation. We appreciate the contribution of the following people: B.O. Offem, B. Bekibele, B.D. Olaosebikan, B.N. Ebonwu, and I.E. Idolor for sample collection.

Author contributions. S.A.N. designed the research, performed the research and wrote the paper; T.X.G. analyzed the data.

\section{Reference}

Adeyemo O.K. 2003 - Consequences of pollution and degradation of Nigerian aquatic environment on fisheries resources - The Environmentalist 23: 297-306.

Agnese J.F. 2000 - Genetic differentiation in West African lagoon fishes - In: Biodiversity and sustainable use offish in the coastal zone (Eds) E.K. Abban, C.M.V: Casal, T.M. Falk, R.S.V. Pullin, ICIARM Conf. Proc. 63: 17-22.

Alves M.J., Coelho H., Collares-Pereira M.J., Coelho M.M. 2001 - Mitochondrial DNA variation in the highly endangered cyprinid fish Anaecypris hispanica: importance for conservation - Heredity 87: 463-473.

Avise J.C. 2000 - Phylogeography: The history and formation of species - Harvard Uinversity Press, Cambridge, Massachusetts London, England, 352 p.

Batista J.S., Alves-Gomes A.J. 2006 - Phylogeography of Brachyplatystoma rousseauxii (Siluriformes Pimelodidae) in the Amazon Basin offers preliminary evidence for the first case of "homing" for an Amazonian migratory catfish - Genet. Mol. Res. 5: 723-740.

Bickham J.W., Smolen M.J. 1994 - Somatic and heritable effects of environmental genotoxins and emergence of 
evolutionary toxicology - Environ. Health. Perspect. 102 (Suppl 12): 25-28.

Bickham J.W., Sandhu S, Hebert P.D.N., Chikhi L., Athwal R. 2000 - Effects of chemical contaminants on genetic diversity in natural populations: implications for biomonitoring and ecotoxicology - Mutat. Res. 463: 33-51.

Billington N., Hebert P.D.N 1991 - Mitochondrial DNA diversity in fishes and its implications for introductions - Can. J. Fish. Aquat. Sci. 48: 80-94.

Buonnacorsi V.P., McDowell J.R., Graves J.E. 2001 - Reconciling patterns of inter-ocean molecular variance from four classes of molecular markers in blue marlin (Makaira nigricans) - Mol. Ecol. 10: 1179-1196.

Cho E.S. Kim J.I. 2006 - Mitochondrial DNA polymorphism of the Japanese anchovy (Engraulis japonicus Temminck \& Schlegel) collected from the Korean offshore and inshore waters - J. Life Sci. 16: 812-827.

Erondu S.E. 1997 - Aspects of the biology of Chrysichthys nigrodigitatus (Lacepede) in the New Calabar River and its aquaculture potentials - Ph. D thesis, University of Nigeria, Nsukka, Nigeria.

Excoffier L., Smouse P.E. 1994 - Using allele frequencies and geographic subdivision to reconstruct gene trees within a species: molecular variance parsimony - Genetics 136 : 343-359.

Excoffier L., Laval G., Schneider S. 2005 - ARLEQUIN (version 3.0): An integrated software package for population genetics data analysis - Evol. Bioinform. Online 1: 47-50.

Excoffier L., Smouse P.E., Quattro J.M. 1992 - Analysis of molecular variance inferred from metric distances among DNA haplotypes: application to human mitochondrial DNA restriction data - Genetics 131: 479-491.

Ezenwa B. 1981 - A study of the reproductive biology of the catfish, Chrysichthys nigrodigitatus (Lacepede) in Nigeria - Ph.D thesis, University of Lagos, 178 p.

Ezenwa B., Ikusemiju L., Olaniyan C.I.O. 1986 - Comparative studies of the catfish, Chrysichthys nigrodigitatus (Lacépéde) in three isolated geographical areas in Nigeria for breeding purposes - In: Aquaculture research in the Africa region (Ed.) E.A. Huisman, Wageningen, The Netherlands: 258-262.

Fu Y.X. 1997 - Statistical tests of neutrality of mutations against population growth, hitchhiking and background selection - Genetics 147: 915-925.

Glenn T.C., Stephan W., Braun M.J. 1999 - Effects of a population bottleneck on whooping crane mitochondrial DNA variation - Conserv. Biol. 13: 1097-1107.

Gyllensten U. 1985 - The genetic structure of fish: differences in the intraspecific distribution of biochemical genetic variation between marine, anadromous, and freshwater species - J. Fish Biol. 26: 691-699.
Harpending H.C. 1994 - Signature of ancient population growth in a low-resolution mitochondrial DNA mismatch distribution - Hum. Biol. 66: 591-600.

Harpending H.C., Sherry S.T., Rogers A.R., Stoneking M. 1993 - The genetic structure of ancient human populations - Curr. Anthropol. 34: 483-496.

Hewitt G.M. 1996 - Some genetic consequences of ice ages, and their role in divergence and speciation - Biol. J. Linn. Soc. 58: 247-276.

Hewitt G.M. 2000 - The genetic legacy of the Quaternary ice ages - Nature 405: 907-913.

Iguchi K., Ohkawa T., Nishida M. 2002 - Genetic structure of land-locked ayu within the Biwa Lake system - Fisheries Science 68: 138-143.

Kimura M. 1980 - A simple method for estimating evolutionary rates of base substitutions through comparative studies of nucleotide sequences - J. Mol. Evol. 16: 111-120.

Koblmüller S., Sefc K.M., Duftner N., Warum M., Sturmbauer C. 2007 - Genetic population structure as indirect measure of dispersal ability in a Lake Tanganyika cichlid - Genetica 130: 121-131.

Kotoulas G., Agnèse J-F., Zouros E. 1991 - Microsatellite variation in the African catfish Chrysichthys nigrodigitatus (LACEPEDE) (Siluroidei, Claroteidae) Aquacult. Fish. Manage. 22: 285-288.

Knight J.T., Nock C.J., Elphinstone M.S., Baverstock P.R. 2009 - Conservation implications of distinct genetic structuring in the endangered freshwater fish Nannoperca oxleyana (Percichthyidae) - Mar. Freshw. Res. 60: 34-44.

Kumar S., Tamura K., Jakobsen I.B., Nei M. 2001 - MEGA2: molecular evolutionary genetics analysis software Bioinformatics 17: 1244-1245.

Lavery S., Moritz C., Fielder D.R. 1996 - Genetic patterns suggest exponential population growth in a declining species - Mol. Biol. Evol. 13: 1106-1113.

Lee W.J., Conroy J., Howell W.H., Kocher T.D. 1995 - Structure and evolution of teleost mitochondrial control regions - J. Mol. Evol. 41: 54-66.

Lévêque C. 1997 - Biodiversity Dynamics and Conservation: The Freshwater Fish of Tropical Africa - Cambridge University Press, Cambridge, 438 p.

Librado P., Rozas J. 2009 - DnaSP v5: a software for comprehensive analysis of DNA polymorphism data Bioinformatics 25: 1452-1452.

Mazumder S.K., Alam M.S. 2009 - High levels of genetic variability and differentiation in hilsa shad, Tenualosa ilisha (Clupeidae, Clupeiformes) populations revealed by PCR-RFLP analysis of the mitochondrial DNA D-loop region - Genet. Mol. Biol. 32: 190-196.

Mo T. 1991 - Anatomy, relationships and systematic of the Bagridae (Teleostei: Siluroidei) with a hypothesis of siluroid phylogeny - Thesis Zoologie 17, Koeltz Scientific Books, Koenigstein, 216 p. 
Moses B.S. 1979 - The Cross River, its ecology and fisheries Proceedings of the International Conference on Kainji Lake and River Basin Development in Africa, 22-25.09.1979, Kainji Lake Research Institute (KLRI), New Bussa, Niger, 366-371.

Moses B.S. 1987 - The influence of flood regime on fish catch and fish communities of the Cross River floodplain ecosystem, Nigeria - Environ. Biol. Fish. 18: 51-65.

Moses B.S. 2001 - The influence of hydroregime on catch, abundance and recruitment of the catfish Chrysichthys nigrodigitatus (Bagridae) and the bonga Ethmalosa fimbriata (Clupeidae) of southeastern Nigeria's inshore waters - Environ. Biol. Fish. 61: 99-109.

Nwafili S.A. 1997 - Fisheries survey of Shiroro Lake, Niger State - M. Tech Thesis, Federal University of Technology, Minna, Nigeria, 98 p.

Nwafili S.A., Soyinka O.O., Gao T.X. 2012 - Levels and patterns of genetic diversity in wild Chrysichthys nigrodigitatus in the Lagos Lagoon complex - Afr. J. Biotechnol. 11: 15748-15754.

Nwafili S.A., Guijing R., Xiang G.T. 2015 - Microsatellite Analysis of Six Populations of Chrysichthys nigrodigitatus from Nigeria - Annual Res. Rev. Biol. 5: 544-552

Obiekezie A.I., Enyenihi U.K. 1988 - Henneguya chrysichthyi sp. nov. (Protozoa: Myxozoa) from the gills of estuarine catfish Chrysichthys nigrodigitatus (Lacépéde). (Pisces: Bagridae) in Nigeria - J. Afr. Zool. 102: 33-42.

Ovenden J.R., Street R. 2003 - Genetic population structure of mangrove jack, Lutjanus argentimaculatus (Forskåll) Mar. Freshwater Res. 54: 127-137.

Posada D., Crandall K.A. 1998 - Model test: testing the model of DNA substitution - Bioinformatics 14: 817-818.

Rogers A.R., Harpending H.C. 1992 - Population growth makes waves in the distribution of pairwise genetic differences - Mol. Biol. Evol. 9: 552-569.

Santos M.C.F., Ruffino M.L., Farias J.P. 2007 - High levels of genetic variability and panmixia of the tambaqui Colossoma macropomum (Cuvier, 1816) in the main channel of the Amazon River - J. Fish Biol. 71(Suppl.): 33-44.
Sefc K.M., Baric S., Salzburger W., Sturmbauer C. 2007 Species-specific population structure in rock-specialized sympatric cichlid species in Lake Tanganyika, East Africa - J. Mol. Evol. 64: 33-49.

Sivalingam S. 1975 - The biology of cultivable brackishwater and marine finfish in Africa - Symposium on aquaculture in Africa, Accra, Ghana. CIFA/IA (Suppl. 1), 204-291.

Slatkin M. 1985 - Gene flow in natural populations - Annu. Rev. Ecol. S. 16: 393-430.

Song N., Nwafili S.A., Gao T.X. 2011 - Genetic diversity and population structure of Chrysichthys nigrodigitatus from Niger Delta based on AFLP analysis - Biochem. Syst. Ecol. 39: 320-327.

Swofford D.L. 1998 - PAUP. Phylogenetic analysis using parsimony (and other methods). Version 4 - Sinauer Associates, Sunderland, MA.

Tajima F. 1989 - Statistical method for testing the neutral mutation hypothesis by DNA polymorphism - Genetics 123: 585-595.

Teugels G.G. 1996 - Taxonomy, phylogeny and biogeography of catfishes (Ostariophysi; Siluroidei): an overview Aquat. Living Resour. 9: 9-34.

Tsipas G., Tsiamis G., Vidalis K., Bourtzis K. 2009 - Genetic differentiation among Greek Lake populations of Carssius gibelio and Cyprinus carpio carpio - Genetica 139: 491-500.

Wang, M., Zhang X., Yang T., Han Z., Yanagimoto T., Gao T. 2008 - Genetic diversity in the mtDNA control region and population structure in the Sardinella zunasi Bleeker - Afr. J. Biotechnol. 24: 4384-4392.

Ward R.D., Woodwark M., Skibinski O.F. 1994 - A comparison of genetic diversity levels in marine, freshwater and anadromous fishes - J. Fish Biol. 44: 213-232.

Watanabe K., Nishida M. 2003 - Genetic population structure of Japanese bagrid catfishes - Ichthyol. Res. 50: 140-148.

Watanabe S., Iida M., Kimura Y., Feunteun E., Tsukamoto K. 2006 - Genetic diversity of Sicyopterus japonicus as revealed by mtDNA sequencing - Coast. Mar. Sci. 30: 473-479. 